\title{
The application of the ahp method in ship system risk estimation
}

\author{
Hoang Nguyen, Ph. D. \\ Gdynia Maritime University
}

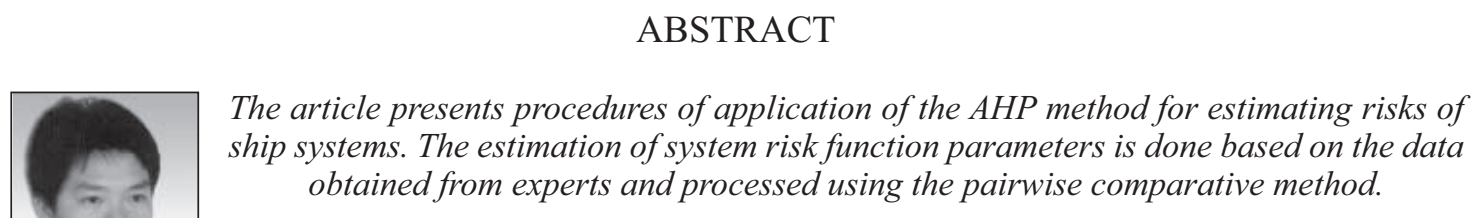

Key words: AHP method, estimation, propulsion risk, expert courts, ship systems

\section{INTRODUCTION}

In sea transport, among numerous factors affecting the safety of navigation, of high importance is the reliability of the propulsion system. The situation when a ship losses its driving ability can lead, in some circumstances, to serious marine accidents, the consequences of which can be deaths of people and/or environment pollution.

The risk of appearance of such an event, which we can refer to as the propulsion risk, depends on the reliability of individual components of the propulsion system and its operators. Estimating the risk of this system is troublesome due to the complexity of the system and the lack of historical data on its reliability. In such cases subjective estimations based on opinions of experts turn out very applicable [4].

In the article, the experts were ship engineers with many years' experience who revealed numbers of propulsion system failures per year and linguistic proportions of contributions of particular subsystems to the total number of disastrous failures of this system. The estimation of risk function parameters for the subsystems included in the data presented by the experts was done by comparing in pairs. This way a proper correlation was obtained between the data referring to the entire system and its particular components (subsystems). The data obtained from comparing in pairs were processed using the Analytical Hierarchical Decision Making Process (AHP) method.

\section{THEORETICAL BACKGROUND}

The AHP method is a method commonly used in multiattribute decision-making. The decision making process in the AHP method consists in ordering of variants, with further aggregation of the obtained ordered sets according to the defined hierarchical structure. The ordered sets are created via comparing in pairs.
The pairwise comparative method consists in comparing individual variants with each other and attributing a number from an earlier defined scale to each pair. The comparison is done by an expert who gives a precise (numerical) or fuzzy estimation to each pair. This estimation expresses individual expert's preference when comparing one variant to the other (Tab. 1).

Tab. 1. Estimations corresponding to experts' preferences, after Saaty (1980)

\begin{tabular}{|c|c|}
\hline Estimation & Preference \\
\hline 1 & Equivalence \\
\hline 3 & $\begin{array}{c}\text { Weak preference of ith variant over } \\
\text { jth variant }\end{array}$ \\
\hline 5 & $\begin{array}{c}\text { Relatively strong preference of ith } \\
\text { variant over jth variant }\end{array}$ \\
\hline 7 & $\begin{array}{c}\text { Definite preference of ith variant } \\
\text { over jth variant }\end{array}$ \\
\hline 9 & $\begin{array}{c}\text { Absolute preference of ith variant } \\
\text { over jth variant }\end{array}$ \\
\hline $2,4,6,8$ & $\begin{array}{c}\text { Intermediate numbers } \\
\text { Inverse numbers to } \\
\text { those above listed }\end{array}$ \\
\hline
\end{tabular}

Let us assume that we have $\mathrm{n}$ variants $\mathrm{W}_{1}, \mathrm{~W}_{2}, \ldots, \mathrm{W}_{\mathrm{n}}$ which are to be ordered. To each pair of variants $\left(\mathrm{W}_{\mathrm{i}}, \mathrm{W}_{\mathrm{j}}\right)$ an expert attributes a number $r_{i j}$ from the set $S=\{1 / 9,1 / 8, \ldots, 1 / 2,1,2$, $\ldots, 8,9\}$ which expresses his/her individual preferences with respect to the ith variant as compared to the jth variant. 
Experts' estimations are used for creating the estimation matrices $\mathbf{R}$ (which are, as a rule, inconsistent).

$$
\mathbf{R}=\left[\mathrm{r}_{\mathrm{ij}}\right]=\left(\begin{array}{cccc}
\mathrm{r}_{11} & \mathrm{r}_{12} & \ldots & \mathrm{r}_{1 \mathrm{n}} \\
\mathrm{r}_{21} & \mathrm{r}_{22} & \ldots & \mathrm{r}_{2 \mathrm{n}} \\
\vdots & \vdots & \vdots & \vdots \\
\mathrm{r}_{\mathrm{n} 1} & \mathrm{r}_{\mathrm{n} 2} & \ldots & \mathrm{r}_{\mathrm{nn}}
\end{array}\right)
$$

Matrix $\mathbf{R}$ is the matrix with inconsistent estimations and has the following properties:

$$
\mathrm{r}_{\mathrm{ij}}>0 ; \mathrm{r}_{\mathrm{ij}}=\frac{1}{\mathrm{r}_{\mathrm{ji}}} \forall \mathrm{i} ; \mathrm{j}=1,2, \ldots, \mathrm{n}
$$

Matrix $\mathbf{R}$ is considered consistent when its elements meet the condition:

$$
\mathrm{r}_{\mathrm{ij} .} \mathrm{r}_{\mathrm{jk}}=\mathrm{r}_{\mathrm{ik}} ; \forall \mathrm{i}, \mathrm{j}, \mathrm{k}=1,2, \ldots, \mathrm{n}
$$

Ordering of variants is obtained as a result of approximation of the estimation matrix $\mathbf{R}$ using matrix $\mathbf{P}$ :

$$
\mathbf{P}=\left[\mathrm{p}_{\mathrm{ij}}\right]=\left(\begin{array}{cccc}
\mathrm{p}_{11} & \mathrm{p}_{12} & \cdots & \mathrm{p}_{1 \mathrm{n}} \\
\mathrm{p}_{21} & \mathrm{p}_{22} & \cdots & \mathrm{p}_{2 \mathrm{n}} \\
\vdots & \vdots & \vdots & \vdots \\
\mathrm{p}_{\mathrm{n} 1} & \mathrm{p}_{\mathrm{n} 2} & \cdots & \mathrm{p}_{\mathrm{nm}}
\end{array}\right)
$$

the elements of which are consistent estimations presented in the form of weight ratios between particular variants:

$$
\mathrm{p}_{\mathrm{ij}}=\frac{\mathrm{p}_{\mathrm{i}}}{\mathrm{p}_{\mathrm{j}}} ; \mathrm{i}, \mathrm{j}=1,2, \ldots, \mathrm{n}
$$

where $p_{i}$ represent weights of particular variants of the order vector $\mathbf{p}$ :

$$
\mathbf{p}=\left(\mathrm{p}_{1}, \ldots, \mathrm{p}_{\mathrm{n}}\right)^{\mathrm{T}}
$$

After arithmetic standardisation we obtain the standardised order vector:

$$
\mathbf{p}^{*}=\left(\mathrm{p}_{1}^{*}, \ldots, \mathrm{p}_{\mathrm{n}}^{*}\right)^{\mathrm{T}}
$$

where:

$$
\mathrm{p}_{\mathrm{i}}^{*}=\frac{\mathrm{p}_{\mathrm{i}}}{\sum_{\mathrm{i}=1}^{\mathrm{n}} \mathrm{p}_{\mathrm{i}}}
$$

Three basic methods which are used for approximating the estimation matrices are the following:

* maximum eigenvalue method [3]

* least square method [3]

* logarithmic least square method $[2,3]$.

\section{a) The maximum eigenvalue method}

This method consists in finding the vector $p$ which fulfils the relation:

$$
\mathbf{R p}=\lambda_{\max } p
$$

where:

$\lambda_{\max }-$ the maximum eigenvalue of matrix $\mathbf{R}$.

\section{b) The least square method}

This method consists in determining a form of matrix $\mathbf{P}$ which is closest to matrix $\mathbf{R}$ and which fulfils the relation:

$$
\min \left[\sum_{i, j=1}^{n}\left(r_{i j}-\frac{p_{i}}{p_{j}}\right)^{2}\right]
$$

\section{c) The logarithmic least square method}

This method consists in determining a form of matrix $\mathbf{P}$ which is closest to matrix $\mathbf{R}$ based on the Euclidean norm in the logarithmic scale. Matrix $\mathbf{P}$ fulfils the relation:

$$
\min \left\{\sum_{i, j=1}^{n}\left[\ln \left(r_{i j}\right)-\ln \left(\frac{p_{i}}{p_{j}}\right)\right]^{2}\right\}
$$

After substituting:

$$
\mathrm{y}_{\mathrm{ij}}=\ln \left(\mathrm{r}_{\mathrm{ij}}\right), \mathrm{x}_{\mathrm{i}}=\ln \left(\mathrm{p}_{\mathrm{i}}\right)
$$

we arrive at the optimisation problem:

$$
\min \left\{I=\sum_{i, j=1}^{n}\left[y_{i j}-x_{i}+x_{j}\right]^{2}\right\}
$$

the solution of which has the form:

$$
\frac{\partial \mathrm{I}}{\partial \mathrm{x}_{\mathrm{k}}}=-2 \sum_{\mathrm{i}=1}^{\mathrm{n}}\left[\mathrm{y}_{\mathrm{kj}}-\mathrm{x}_{\mathrm{k}}+\mathrm{x}_{\mathrm{j}}\right]=0
$$

After introducing the condition of geometrical standardisation:

$$
\prod_{\mathrm{i}=1}^{\mathrm{n}} \mathrm{p}_{\mathrm{i}}=1 ;\left(\sum_{\mathrm{j}=1}^{\mathrm{n}} \mathrm{x}_{\mathrm{j}}=0\right)
$$

Equation (9) takes the form:

$$
\sum_{\mathrm{j}=1}^{\mathrm{n}} \mathrm{y}_{\mathrm{kj}}=\mathrm{nx}_{\mathrm{k}} \text { or } \mathrm{x}_{\mathrm{k}}=\frac{1}{\mathrm{n}} \sum_{\mathrm{j}=1}^{\mathrm{n}} \mathrm{y}_{\mathrm{kj}} ; \mathrm{k}=1, \ldots, \mathrm{n}
$$

Finally, after taking into account (8) we get the variant order vector:

$$
\mathrm{p}_{\mathrm{i}}=\mathrm{e}^{\mathrm{x}_{\mathrm{i}}}=\left(\prod_{\mathrm{j}=1}^{\mathrm{n}} \mathrm{r}_{\mathrm{ij}}\right)^{\frac{1}{\mathrm{n}}} ; \mathrm{i}=1, \ldots, \mathrm{n}
$$

For a large number of experts estimating a given pair of variants, the estimations made by individual experts are considered equivalent to each other. Then the task is limited to the following form:

where:

$$
\min \left\{\sum_{\mathrm{i}, \mathrm{j}=1}^{\mathrm{n}} \sum_{\mathrm{k}=1}^{\mathrm{m}_{\mathrm{ij}}}\left[\ln \left(\mathrm{r}_{\mathrm{ijk}}\right)-\ln \left(\frac{\mathrm{p}_{\mathrm{i}}}{\mathrm{p}_{\mathrm{j}}}\right)\right]^{2}\right\}
$$

$\mathrm{m}_{\mathrm{ij}}-$ the number of estimations concerning the pair $(\mathrm{i}, \mathrm{j})$.

After introducing substitutions:

$$
y_{i j k}=\ln \left(r_{i j k}\right), x_{i}=\ln \left(p_{i}\right)
$$

we arrive at the optimisation problem:

$$
\min \left\{I=\sum_{i, j=1}^{n} \sum_{k=1}^{m_{i j}}\left[y_{i j k}-x_{i}+x_{j}\right]^{2}\right\}
$$

the solution of which has the form:

$\frac{\partial \mathrm{I}}{\partial \mathrm{x}_{1}}=-2 \sum_{\mathrm{j}=1}^{\mathrm{n}} \sum_{\mathrm{k}}^{\mathrm{m}_{\mathrm{ij}}}\left[\mathrm{y}_{\mathrm{ljk}}-\mathrm{x}_{1}+\mathrm{x}_{\mathrm{j}}\right]=0 ; 1=1,2, \ldots, \mathrm{n}$

The set of equations (15) is transformed to the set of standard equations:

$x_{i} \sum_{j=1, j \neq i}^{n} m_{i j}-\sum_{j=1, j \neq i}^{n} m_{i j} x_{j}=\sum_{j=1, j \neq i}^{n} \sum_{k=1}^{m_{i j}} y_{i j k} ; i=1,2, \ldots, n$ 
In matrix notation the set (16) has the form:

$$
\mathrm{Ax}=\mathbf{b}
$$

where:

$$
\begin{gathered}
\mathbf{b}=\left[\mathrm{b}_{\mathrm{i}}\right] ; \mathrm{b}_{\mathrm{i}}=\sum_{\mathrm{j}=1, \mathrm{j} \neq \mathrm{i}}^{\mathrm{n}} \sum_{\mathrm{k}=1}^{\mathrm{m}_{\mathrm{ij}}} \mathrm{y}_{\mathrm{ijk}} ; \mathrm{i}=1,2, \ldots, \mathrm{n} \\
\mathbf{A}=\left(\begin{array}{cccc}
\sum_{\mathrm{j}=1, \mathrm{j} \neq 1}^{\mathrm{n}} \mathrm{m}_{1 \mathrm{j}} & -\mathrm{m}_{12} & \ldots & -\mathrm{m}_{1 \mathrm{n}} \\
-\mathrm{m}_{21} & \sum_{\mathrm{j}=1, \mathrm{j} \neq 2}^{\mathrm{n}} \mathrm{m}_{2 \mathrm{j}} & \ldots & -\mathrm{m}_{2 \mathrm{n}} \\
\vdots & \vdots & \vdots & \vdots \\
-\mathrm{m}_{\mathrm{n} 1} & -\mathrm{m}_{\mathrm{n} 2} & \ldots & \sum_{\mathrm{j}=1, \mathrm{j} \neq \mathrm{n}}^{\mathrm{n}} \mathrm{m}_{\mathrm{nj}}
\end{array}\right)
\end{gathered}
$$

Hence, the variant order vector can be determined from the equation:

$$
\mathbf{p}=\mathrm{e}^{\mathbf{x}}=\mathrm{e}^{\mathbf{A}^{-1} \mathbf{b}}
$$

[2] has shown that, despite its popularity, the maximum eigenvalue method reveals a weakness, namely it does not have the property of relation commutation, which means that the operation of estimation matrix transposition leads to different results. At the same time the least square method does not produce a unique solution.

The logarithmic least square method is reduced to the geometric mean method for a large number of experts, as well as to the estimation matrix without missing data. The geometric mean method is a symmetrical transformation and produces the unique solution, irrelevant of scale inversion or changes in the order of particular aggregation operations. It is compatible with the estimation method of the highest credibility, which gives the reasons for its use from the point of view of the statistics. Further in the article, the logarithmic least square method is used for estimating the subjective ship propulsion risk.

Among presently available computer codes which make use of the AHP method for decision-making, the codes which are preferred are Expert Choice and Criterium Decision Plus. Due to limitations concerning the numbers of variants in those codes, a computer code was developed based on calculating algorithms which make use of the logarithmic least square method.

\section{APPLICATION}

The AHP method was used for estimating proportions of contributions of individual subsystems and units in the reliability structure of the ship propulsion system. The data were obtained from a group of 47 experts (ship engineers) using a specially prepared questionnaire [ESREL 2008].

The experts revealed their opinions on the proportions of contributions of particular subsystems in the total number of failures of the examined system in the form of linguistic values (very small, small, medium, big, very big). These values express experts' preferences concerning the contributions of particular subsystems as the causes of propulsion system failures (Tab. 2).

These data are compared in pairs and scaled using the assumed 5-stage scale to create the estimation matrices. A sample matrix which was created for the $\mathrm{k}$-th expert is given

\begin{tabular}{|c|c|c|c|c|c|c|}
\hline No. & $\begin{array}{c}\text { Name of } \\
\text { subsystem }\end{array}$ & $\begin{array}{c}\text { very } \\
\text { small } \\
\text { /zero } \\
\end{array}$ & small & medium & big & $\begin{array}{c}\text { very } \\
\text { big }\end{array}$ \\
\hline 1 & $\begin{array}{c}\text { Fuel oil } \\
\text { subsystem }\end{array}$ & & & & $\mathrm{X}$ & \\
\hline 2 & $\begin{array}{l}\text { Seawater } \\
\text { cooling } \\
\text { subsystem }\end{array}$ & & $\mathrm{x}$ & & & \\
\hline 3 & $\begin{array}{c}\text { Low } \\
\text { temperature } \\
\text { freshwater } \\
\text { cooling } \\
\text { subsystem }\end{array}$ & & $\mathrm{x}$ & & & \\
\hline 4 & $\begin{array}{c}\text { High } \\
\text { temperature } \\
\text { freshwater } \\
\text { cooling } \\
\text { subsystem } \\
\end{array}$ & & $\mathrm{x}$ & & & \\
\hline 5 & $\begin{array}{l}\text { Starting air } \\
\text { subsystem }\end{array}$ & & & $\mathrm{x}$ & & \\
\hline 6 & $\begin{array}{c}\text { Lubrication } \\
\text { oil } \\
\text { subsystem }\end{array}$ & & & $\mathrm{x}$ & & \\
\hline 7 & $\begin{array}{c}\text { Cylinder } \\
\text { lubrication } \\
\text { oil } \\
\text { subsystem }\end{array}$ & & $\mathrm{x}$ & & & \\
\hline 8 & $\begin{array}{c}\text { Electric } \\
\text { power } \\
\text { subsystem }\end{array}$ & & & & $\mathrm{x}$ & \\
\hline 9 & $\begin{array}{c}\text { Main } \\
\text { engine }\end{array}$ & & & & $\mathrm{x}$ & \\
\hline 10 & $\begin{array}{c}\text { Main } \\
\text { engine } \\
\text { remote } \\
\text { control } \\
\text { subsystem } \\
\end{array}$ & & & $\mathrm{x}$ & & \\
\hline 11 & $\begin{array}{c}\text { Propeller } \\
\text { and shaft } \\
\text { line }\end{array}$ & & $\mathrm{x}$ & & & \\
\hline
\end{tabular}
below:
Tab. 2. Linguistic experts' opinions on the contributions of particular subsystems in total number of system failures.

$\mathbf{R}_{\mathbf{k}}=\left[\mathrm{r}_{\mathrm{ijk}}\right]=\left(\begin{array}{ccccccccccc}1 & 5 & 5 & 5 & 3 & 3 & 5 & 1 & 1 & 3 & 5 \\ 1 / 5 & 1 & 1 & 1 & 1 / 3 & 1 / 3 & 1 & 1 / 5 & 1 / 5 & 1 / 3 & 1 \\ 1 / 5 & 1 & 1 & 1 & 1 / 3 & 1 / 3 & 1 & 1 / 5 & 1 / 5 & 1 / 3 & 1 \\ 1 / 5 & 1 & 1 & 1 & 1 / 3 & 1 / 3 & 1 & 1 / 5 & 1 / 5 & 1 / 3 & 1 \\ 1 / 3 & 3 & 3 & 3 & 1 & 1 & 3 & 1 / 3 & 1 / 3 & 1 & 3 \\ 1 / 3 & 3 & 3 & 3 & 1 & 1 & 3 & 1 / 3 & 1 / 3 & 1 & 3 \\ 1 / 5 & 1 & 1 & 1 & 1 / 3 & 1 / 3 & 1 & 1 / 5 & 1 / 5 & 1 / 3 & 1 \\ 1 & 5 & 5 & 5 & 3 & 3 & 5 & 1 & 1 & 3 & 5 \\ 1 & 5 & 5 & 5 & 3 & 3 & 5 & 1 & 1 & 3 & 5 \\ 1 / 3 & 3 & 3 & 3 & 1 & 1 & 3 & 1 / 3 & 1 / 3 & 1 & 3 \\ 1 / 5 & 1 & 1 & 1 & 1 / 3 & 1 / 3 & 1 & 1 / 5 & 1 / 5 & 1 / 3 & 1\end{array}\right)_{\mathbf{k}}$


Then the estimation matrices $\mathbf{R}$ are approximated using the order vector component ratio matrix. The estimation matrix approximation was performed using the logarithmic least square method for the case of a large number of experts. Matrix $\mathbf{A}$ is obtained in the form:

$$
\mathbf{A}=\left[\mathrm{a}_{\mathrm{ij}}\right]=\left(\begin{array}{ccccccccccc}
1 & 1 & 1 & 1 & 1 & 1 & 1 & 1 & 1 & 1 & 1 \\
-47 & 470 & -47 & -47 & -47 & -47 & -47 & -47 & -47 & -47 & -47 \\
-47 & -47 & 470 & -47 & -47 & -47 & -47 & -47 & -47 & -47 & -47 \\
-47 & -47 & -47 & 470 & -47 & -47 & -47 & -47 & -47 & -47 & -47 \\
-47 & -47 & -47 & -47 & 470 & -47 & -47 & -47 & -47 & -47 & -47 \\
-47 & -47 & -47 & -47 & -47 & 470 & -47 & -47 & -47 & -47 & -47 \\
-47 & -47 & -47 & -47 & -47 & -47 & 470 & -47 & -47 & -47 & -47 \\
-47 & -47 & -47 & -47 & -47 & -47 & -47 & 470 & -47 & -47 & -47 \\
-47 & -47 & -47 & -47 & -47 & -47 & -47 & -47 & 470 & -47 & -47 \\
-47 & -47 & -47 & -47 & -47 & -47 & -47 & -47 & -47 & 470 & -47 \\
-47 & -47 & -47 & -47 & -47 & -47 & -47 & -47 & -47 & -47 & 470
\end{array}\right)
$$

Vector $\mathbf{b}$, vector $\mathbf{x}$ and the weight vector of standardised proportions of contributions of particular subsystems as causes of propulsion system failures, which were determined based on opinions obtained from a group of 47 experts, are as follows:

$$
\mathbf{b}=\left(\begin{array}{c}
0 \\
-274.95 \\
-327.13 \\
-94.04 \\
71.12 \\
-40.97 \\
-264.76 \\
478.40 \\
508.06 \\
212.73 \\
-568.94
\end{array}\right), \mathbf{x}=\left(\begin{array}{c}
0.5812 \\
-0.5318 \\
-0.6327 \\
-0.1819 \\
0.1375 \\
-0.0792 \\
-0.5121 \\
0.9253 \\
0.9827 \\
0.4114 \\
-1.1004
\end{array}\right), \mathbf{p}^{*}=\left(\begin{array}{c}
0.1329 \\
0.0436 \\
0.0394 \\
0.0619 \\
0.0853 \\
0.0686 \\
0.0445 \\
0.1876 \\
0.1986 \\
0.1122 \\
0.0247
\end{array}\right)
$$

Fig. 1 presents the estimated subsystem weights in the propulsion system function loss risk model, which were determined based on opinions given by 47 experts.

It was assumed that the system unreliability function has exponential probabilities of the time to first failure. The exponential distribution of this time is characteristic for normal operation of numerous classes of systems, including ship systems (Gniedienko B.W et al., 1965).

$$
\mathfrak{R}(\mathrm{t})=\mathrm{P}\{\tau<\mathrm{t})\}=1-\mathrm{e}^{-\lambda \mathrm{t}} ; \mathrm{t} \geq 0
$$

where:

$$
\begin{array}{lll}
\lambda- & \text { system failure rate } \\
\tau & - & \text { random variable representing the time to failure. }
\end{array}
$$

This model takes also into account standstills which are connected with renewals of the ship and its equipment and which are negligibly short compared to the ship maintenance time. Then the system failure rate $\lambda$ can be evaluated from the theorem about asymptotic behaviour of the recovery process (Gniedienko B.W. \& Bielajew J.K. \& Sołowiew A.D. 1965):

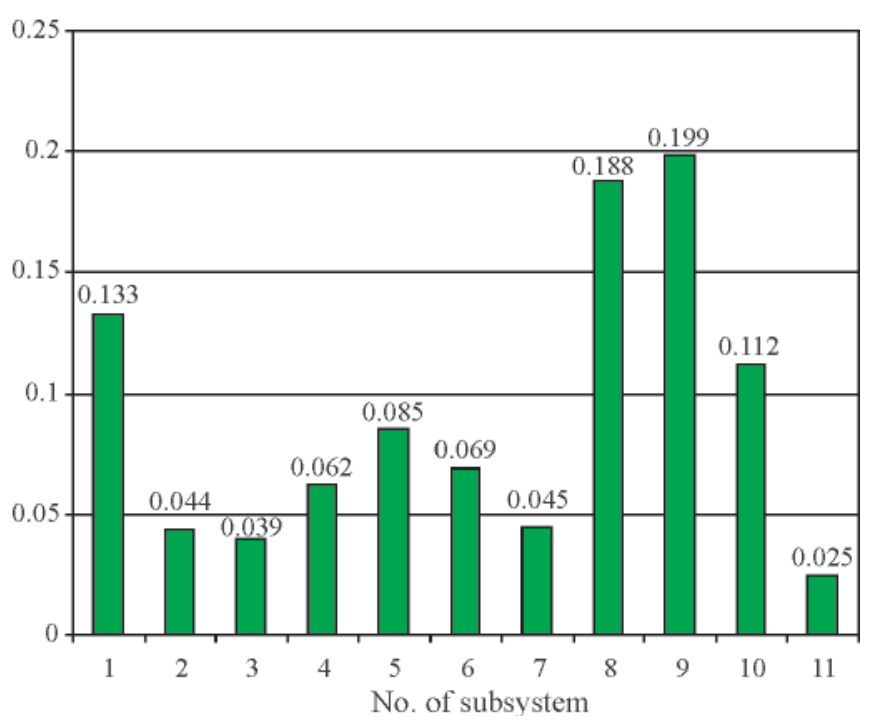

Fig. 1. Subsystem weights determined using the logarithmic least square method for the opinions obtained from 47 experts

$$
\lim _{t \rightarrow \infty} \frac{E[N(t)]}{t}=\frac{1}{T_{0}}=\lambda
$$

where:

$\mathrm{T}_{\mathrm{o}} \quad-$ mean time to failure

$\mathrm{N}(\mathrm{t}) \quad$ - number of system failures.

From the data revealed by the experts we get $\lambda=3.34575$ E -04 1/h.

The obtained subsystem contribution order vector can be written in the form:

$$
\mathbf{p}=\mathrm{p}^{*}=\left(\mathrm{p}_{1}, \mathrm{p}_{2}, \ldots \mathrm{p}_{\mathrm{i}}, \ldots \mathrm{p}_{\mathrm{n}}\right)
$$

where:

$\mathrm{p}_{\mathrm{i}}-$ contribution of the ith subsystem as the cause of system failure

$\mathrm{n} \quad-$ number of subsystems.

The system failure rate can be determined from the relation:

$$
\lambda_{\mathrm{i}}=\lambda \mathrm{p}_{1}, \mathrm{i}=1,2, \ldots, \mathrm{n}
$$


The results of the calculations are shown in Tab. 3 as the estimated weights and subsystem failure rates in the propulsion system function loss risk model.

Tab. 3. Subsystem failure rates

\begin{tabular}{|c|c|c|c|}
\hline No. & Subsystem & $\mathbf{p}_{\mathbf{i}}$ & $\lambda \mathbf{E}-05$ \\
\hline 1 & Fuel oil subsystem & 0.132970 & 4.52026 \\
\hline 2 & $\begin{array}{l}\text { Seawater cooling } \\
\text { subsystem }\end{array}$ & 0.043692 & 1.48517 \\
\hline 3 & $\begin{array}{l}\text { Low temperature } \\
\text { freshwater cooling } \\
\text { subsystem }\end{array}$ & 0.039497 & 1.34260 \\
\hline 4 & $\begin{array}{l}\text { High temperature } \\
\text { freshwater cooling } \\
\text { subsystem }\end{array}$ & 0.061996 & 2.10739 \\
\hline 5 & $\begin{array}{l}\text { Starting air } \\
\text { subsystem }\end{array}$ & 0.085332 & 2.90062 \\
\hline 6 & $\begin{array}{l}\text { Lubrication oil } \\
\text { subsystem }\end{array}$ & 0.068698 & 2.33519 \\
\hline 7 & $\begin{array}{l}\text { Cylinder lubrication } \\
\text { oil subsystem }\end{array}$ & 0.044561 & 1.51474 \\
\hline 8 & $\begin{array}{l}\text { Electric power } \\
\text { subsystem }\end{array}$ & 0.187603 & 6.37703 \\
\hline 9 & Main engine & 0.198681 & 6.75360 \\
\hline 10 & $\begin{array}{l}\text { Main engine remote } \\
\text { control subsystem }\end{array}$ & 0.112219 & 3.81457 \\
\hline 11 & $\begin{array}{l}\text { Propeller and shaft } \\
\text { line }\end{array}$ & 0.024742 & 0.84103 \\
\hline
\end{tabular}

\section{CONCLUSIONS}

The article presents the procedures of application of the pairwise comparative method to the ship system risk estimation. These methods are extremely applicable when estimating expert data, which are, as a rule, inconsistent and/ or burdened with error. Although in general these methods are well known and in common use, the novelty of the here presented work consists in the application of the logarithmic least square method to ordering variants, which is reduced to the geometrical standardisation. The applied procedure secures proper correlation between opinions presented by many different experts. In case some data are missing this method can also be used directly, and the missing data are assumed as consistent with the resultant order.

Currently, activities are in progress in the Department of Engineering Sciences, Gdynia Maritime University, upon a neuron-fuzzy model of the ship propulsion risk. The estimated parameters obtained from the expert base using the AHP method are the input data for this model.

\section{BIBLIOGRAPHY}

1. Gniedienko B.W., Bielajew J.K., Sołowiew A.D.: Mathematical methods in reliability theory (in Polish). Warsaw: Wydawnictwa Naukowo-Techniczne, 1968

2. Kwiesielewicz M.: Analytic hierarchical decision-making process. Fuzzy and non-fuzzy pairwise comparison (in Polish). PAS Systems Research Institute: Warsaw, 2002

3. Saaty T.L.: The Analytic Hierarchy Process. New York et al: McGraw-Hill, 1980

4. Mazzuchi T., Linzey W., Brauning A.: A paired comparison experiment for gathering expert judgement for an aircraft wiring risk estimation. Reliability engineering \& System safety 93, 2008

\section{CONTACT WITH THE AUTHOR}

Nguyen Hoang, Ph. D.

Faculty of Marine Engineering, Gdynia Maritime University

Morska 81/87

81-225 Gdynia, POLAND

e-mail : hoang@am.gdynia.pl 